DOI: $10.20472 / E F C .2019 .012 .015$

\author{
MARIA GUADALUPE LUGO-SANCHEZ \\ University Center for Economic and Administrative Sciences, University of Guadalajara, Mexico
}

\title{
CHALLENGES OF THE EVALUATION SYSTEM IN MEXICO
}

\begin{abstract}
:
Evaluation has an important role in society, because it provides affirmations of value, merit, progress, accreditation, responsibility, and when necessary, has the power to finish social programs that do not work, or, on the contrary, expand programs that do. Although the practice of evaluation is old, it is considered that the discipline is in a young stage, as the first efforts to formally develop evaluation theory go back to the decade of the 40s. In Latin America, the institutionalization of evaluation took place at the end of the 20th century, although the process accelerated during the first years of the 21 st century. The growing interest was a result of the need to evaluate the social programs that had been instated with the purpose of alleviating the consequences of the economic crisis that the Latin American countries were going through. This gradual process of progress in social programs in Mexico has given rise to the creation of institutions responsible for formalizing the evaluation processes in the country. Despite the above, the desired maturity in terms of evaluation has not been achieved. The purpose of this document is to review the challenges of the current evaluation system in Mexico.
\end{abstract}

\section{Keywords:}

Evaluation of Fiscal Policies, Social Programs, Evaluation Theory

JEL Classification: $\mathrm{H} 30, \mathrm{H} 43, \mathrm{H} 53$ 
"If you do not know much about evaluation theory, you're not an evaluator. Maybe you are a great methodologist, a wonderful philosopher or a very efficient program administrator. But you are not an evaluator. To be an evaluator, you need to have a knowledge base that makes the field unique. That unique knowledge base is the evaluation theory "-W.R.

\section{Shadish}

\section{Introduction}

Evaluation has an important role for society, because it allows to provide affirmations of value, merit, progress, accreditation, responsibility, and when necessary, is in charge of providing the bases to finish social programs that do not work, or, on the contrary, expand programs that do work. Although the practice of evaluation is old, it is considered that the discipline is in a young stage, as the first efforts to formally develop evaluation theory go back to the decade of the 40 s.

In Latin America, the institutionalization of evaluation took place at the end of the 20th century, although the process accelerated as of the first years of the 21st century as a result of the need to evaluate the social programs that had been put in place with the purpose of alleviating the consequences of the economic crisis that the Latin American countries were facing. During the $70 \mathrm{~s}$, most of the governments of the region allocated an important amount of financial resources to social programs focused on the design of plans and programs for social development, which were not being evaluated; thus, the first monitoring and evaluation efforts were focused mainly on the design of these programs. International organizations such as the Inter-American Development Bank (IDB) and the World Bank contributed to the financing of these social programs, thus generating demand for monitoring and evaluation, because the financing offered was conditional on the projects including evaluation mechanisms (Pérez and Maldonado Trujillo, 2015).

Mexico has stood out in Latin America for the progress made in the institutionalization of the evaluation of social programs and policies since the second half of the $90 \mathrm{~s}$. This strengthening has occurred as a result of a process of legal reforms that have emanated from political and social changes in the country. It also stands out for its PROGRESA social program, focused on the population living in extreme poverty and characterized by promoting education, improving the diet and health of its beneficiaries through conditional cash transfers; This program has functioned as a model for other countries in Latin America and has the peculiarity of having included the planning of the impact evaluation from the design of the program. 
This gradual process of progress in social programs in Mexico has given rise to the creation of institutions responsible for formalizing the evaluation processes in the country. Despite the above, the desired maturity in terms of evaluation has not been achieved. The purpose of this essay is to review the challenges of the current evaluation system in Mexico.

\section{Literature review}

The field of Evaluation is relatively young: the first reference to the development of evaluation theory is in 1942 by Ralph Tyler, author of the objective-oriented evaluation model and first in his field to develop the first systematic method of educational evaluation, during a research conducted at the University of Ohio entitled "Eight Year Study" (Pérez, 2007).

Hogan, (2007) reviews the evolution of the discipline based on the work of Madaus, Stufflebeam, \& Kellaghan, (2000) and identifies and describes the development of the seven periods of the program evaluation, and contributes to the previous revision by analyzing the main approaches to evaluation in the 21 st century.

The definition of evaluation has evolved over time, implementing elements from the different approaches where the subject has been developed. The evaluation has been associated to the measurement of the scope of objectives, or to the tests (performed in the classrooms) or in the case of other disciplines, when referring to the experimental processes of measurement. It is precisely in the educational field where the largest number of program evaluations have been conducted, mainly in the United States, Canada and the United Kingdom.

Later, evaluation was considered as a tool that allows to obtain qualitative information valuable for the decision-making process. However, limiting the definition to only "objectives' achievement" seriously limits the evaluation, as it can lead to failure if said objectives are corrupted, dysfunctional, or if they are not aimed to satisfying the needs of the beneficiaries (Stufflebeam and Coryn, 2014). Considering the aforementioned, theorists have proposed broader definitions, that allow to cover (in a more complete way) the evaluation term. Scriven defines it as "the systematic determination of merit, value or significance", because, for evaluation, the values and standards offer a filter that provides meaning to the information. Over time, the process of evolution of evaluation of programs has been dynamic. The field has matured significantly in recent decades, moving from traditional summative approaches to more sophisticated training approaches. 


\section{Social policy and evaluation in Mexico}

\subsection{Social policies in Mexico}

Social policies constitute a particular type of public policy, whose ultimate goal is the achievement of social welfare through strategies of redistribution of wealth and income to promote a continuous improvement of the living conditions of the population. Promoted in Europe within the framework of the welfare state at the end of the Second World War, its main contribution lies in the expansion of social rights and the procurement of acceptable conditions of life for the whole of society.

In this sense, social policy is a function assumed by the Mexican State. The Mexican industrialization process of the 1940s resulted in an increase in economic growth rates, accompanied by a poor distribution of income between the countryside and the city, and between social groups, resulting in an inequality gap that would deepen with the pass of the time. During the decade of the 1980s, the lack of income caused by the economic crisis that prevailed in Latin America caused the crisis of the welfare state model, resulting in proposals for the provision of social services by public and private entities. By the end of the decade, universal policies had been replaced by programs focused on alleviating the situation of extreme poverty that showed alarming dimensions in Mexico. The objectives of this new social policy proposed in the short term included monetary transfers, while, in the long term, it was thought to boost human and social capital, through investments in education, food, healthcare and infrastructure.

The first specific social programs were established by President Lopez Portillo, who resumed the Public Investment Program for Rural Development (PIDER) proposed by President Echeverria and which is considered to be the antecedent of all programs to combat poverty in Mexico. Lopez Portillo also proposed the creation of a Coordination of the General Plan of Depressed Areas and Marginalized Groups (COPLAMAR) that had two main objectives: (1) to apply studies to detect the essential needs of the population in areas of extreme poverty; and (2) to make proposals to coordinate and improve the functioning of the dependencies and entities that were in charge of approved social programs (Cardozo Brum, 2006). COPLAMAR, together with other Mexican institutions such as the IMSS, the SEP, the STPS and the Secretariat of Human Settlements and Public Works managed to provide care for almost 4 million Mexicans through the provision of health and educational services, training and employment, and drinking water in order to achieve the aforementioned objectives. However, the evaluation of these programs was limited to the design phase because, until the first half of the decade of the 90s there was no clear structure for the evaluation in Mexico. 


\subsection{The evaluation of social programs in Mexico}

The importance of the evaluation of social programs can be identified in 4 main aspects: (1) the magnitude of the social expenditure that implies; (2) the percentage of social spending that is effectively redistributive; (3) the efficiency in the application of said expense; and (4) the impact it has on the solution of the problem it is trying to solve. This means that there can be no relevant results if the programs do not have enough funds. But even if resources were available, spending them will not be enough, because often, many of those resources are wasted in processes that prevent them from reaching the target population. Once the resources are approved, it is hard to trace if the resources reach the true beneficiaries and, in a very few occasions, the effectiveness that they have to solve the problem that motivated the creation of the program, can be known (Cohen, 2001).

The first efforts of evaluation of social programs that are known in Mexico were carried out by LICONSA, DICONSA and the National Institute of Solidarity, for the period 1995 $2000^{1}$, however, they are not available for public consultation. Other programs that have been subject to various evaluations are PRONASOL and PROGRESA; the process and results of the latter have allowed for a deeper understanding of the evaluation approach later conducted in posterior social programs for development, as is the case of OPORTUNIDADES.

The evaluation of social programs received a boost in 2004 as a result of the publication of the General Law of Social Development (LGDS) and the beginning of the work of the National Council for the Evaluation of Social Development Policy (Coneval) in 2006. Then, the LGDS formally requested to conduct the evaluation of social policies in Mexico. These two events established the legal, institutional, regulatory and normative bases that provide the framework to organize and evaluate social policy. The Law grants the Coneval the broad and substantive power to take charge of the evaluation of social policies, being able to "carry it out by itself or through one or several independent organizations", with the goal to "periodically reviewing the social objective of the programs, goals and actions of the Social Development Policy, to correct them, modify them, add them, reorient them or suspend them totally or partially" (DOF, 2004). In addition, Coneval participates in tasks such as: approval of performance indicators; evaluation planning; preparation, dissemination and monitoring of evaluation methodologies; execution and monitoring of external evaluations; selection of external evaluators, and dissemination, coordination and monitoring of the results of the evaluations (suggestions and recommendations) for the agencies operating the programs. Coneval has a legal obligation to annually evaluate the coverage, quality and impact of all social development programs subject to Operating Rules. Initially it had an

\footnotetext{
${ }^{1}$ In 1995 President Ernesto Zedillo acknowledges in a speech, the need for the evaluation of social programs based on the results.
} 
inventory of 89 social programs in 2004; by 2015 registered $233^{2}$ programs, which led to apply, with some exceptions, very simplified and standardized evaluations, such as specific performance evaluations (Cardozo Brum, 2013). Table 1 shows the main types of evaluations conducted in Mexico:

Table 1: Main types of Evaluations in Mexico

MAIN TYPES OF EVALUATIONS EMPLOYED IN MEXICO

\begin{tabular}{|l|l|l|}
\hline Diagnostic Evaluation & Evaluation of indicators & Specific Evaluation \\
\hline Evaluation of Design & Evaluation of process & Strategic Evaluation \\
\hline
\end{tabular}

Evaluation of

Consistency and Results Impact Evaluation Cost-Benefit Evaluation

Elaborated by the author based in Maldonado and Pérez, 2015.

Regarding the cost of evaluations in Mexico, it varies greatly according to the type of evaluation that is being conducted, as can be seen in table 2 .

\section{Table 2: Type and costs of Evaluations in Mexico (U.S. Dollars)}

\begin{tabular}{l|r}
\hline Type of Evaluation & Average cost 2011-2019 \\
\hline Consistency and Results & $\$ 27,587.12$ \\
\hline Design & $\$ 15,892.60$ \\
\hline Specific Evaluation & $\$ 6,820.72$ \\
\hline Impact & $\$ 129,579.34$ \\
\hline Process & $\$ 82,229.30$ \\
\hline TOTAL AVERAGE (USD) & $\$ 52,421.82$ \\
\hline
\end{tabular}

Elaborated by the author with data from https://www.transparenciapresupuestaria.gob.mx/es/PTP/evaluaciones

The average cost of evaluations in Mexico (calculated for the period 2011-2019) is $\$ 52,421.82$ USD as shown in Table 2; however, the costs varies depending on the type and complexity of the evaluation.

The impact evaluations that have been carried out in Mexico are relatively scarce. Due to the time and effort required to apply them, they incur in very high costs. For instance, the total cost of the impact evaluation for OPORTUNIDADES (previously known as PROGRESA) was $\$ 1,519,479.55$ USD, and took 2 years to be completed.

Among the main results obtained from the program, the following stand out: positive effects on household income, decrease in school desertion and infant malnutrition, as well as perseverance in the participation of beneficiaries. However, an important

\footnotetext{
${ }^{2}$ http://www.coneval.org.mx/evaluacion/ipfe/Paginas/default.aspx
} 
discrepancy is detected between the averages of the beneficiaries and the state averages in education. The high cost of the impact evaluation was also criticized, as it was considered that the resources could have been assigned to the program, with a greater number of beneficiaries.

At a state-level, Evalua Jalisco is an organization created with the purpose of evaluating and monitoring social programs and public policies in the State of Jalisco and aims to improve management, results and impact of programs and policies that have impact on the quality of life and the development of the state. The evaluations are public and can be consulted on their website. In addition, it has public funds that allows Evalua Jalisco's evaluative practice to be financed, which is conducted independently and technically. This fund, created in 2015 by the State Government, is exclusively dedicated to the fulfillment of the annual evaluation program.

To date, Evalua Jalisco reports 90 evaluations in the period 2013 to 2018. Table 4 shows the number of evaluations that have been carried out, by type of evaluation. In Jalisco, the average cost of evaluations is $\$ 12,239.17$ USD with a range of between $\$ 1,650$ and $\$ 65,000$ USD.

\section{Table 4: Types of evaluations by Evalua Jalisco (2013-2019)}

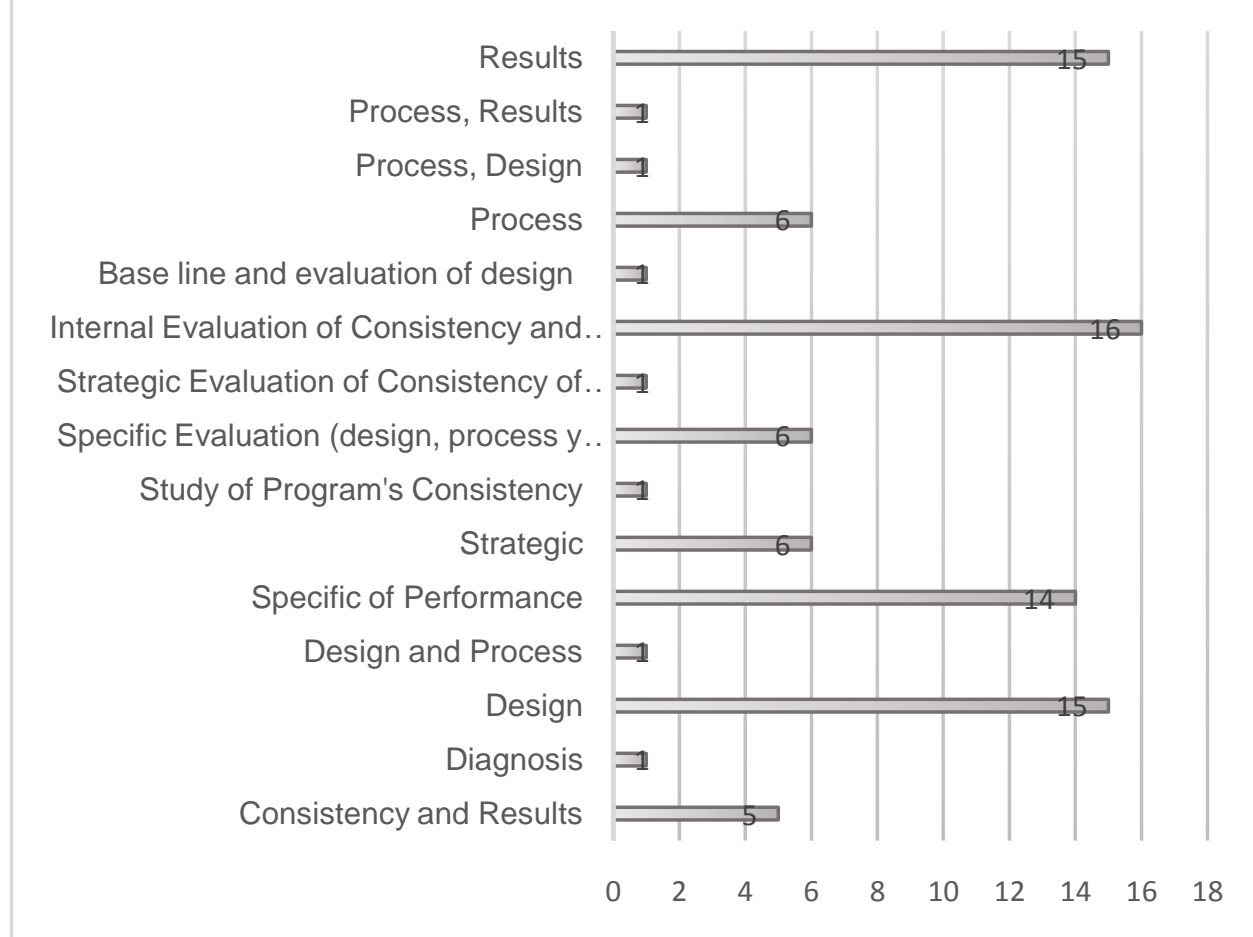

Elaborated by the author with data from Evalua Jalisco ${ }^{3}$

\footnotetext{
${ }^{3}$ https://seplan.app.jalisco.gob.mx/evalua/evaluacion/listadoevaluaciones?field tipo de evaluacion target id=All\&field ano target id=All\&field dependencia responsable de tar

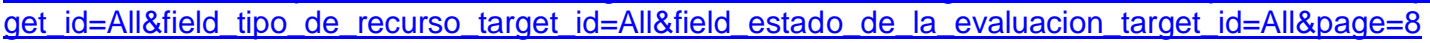


The evaluations reported by Evalua Jalisco are carried out by independent consultants who, although complying with the terms of reference, do not conduct a thorough literature review of evaluation theory.

\section{Conclusions}

The results of the first evaluations in Mexico had a symbolic rather than an instrumental use, which is explained by the lack of maturity in the practice of evaluation, and also to the political origin of these early efforts that tried to prevent the use of social programs for electoral purposes and to the benefit of certain political parties.

Although comparatively, Mexico is one of the countries in Latin America that is most advanced in terms of evaluation and has a structure that gives a solid legal framework to the processes through the creation of various institutions, it is still necessary to theoretically reinforce the evaluation processes. Coneval is a clear example of progress in terms of evaluation in the country by developing operating rules and establishing general guidelines for monitoring and evaluation of social programs and policies, in addition to the joint work carried out with other institutions interested in participating in the evaluation process in the country.

One of the main challenges facing evaluation in Mexico is the limited use that is given to evaluations; although they are recognized as a necessary process to measure the results of a social program, they rarely transcend into processes of modification, expansion or even cancellation of social programs.

On the other hand, information about the process that follow the evaluations, such as methodology, quality of the results, among others, are not disclosed in a timely manner. Therefore, Cohen, (2001) argues that there is no clarity about the benefits of evaluation in Latin America; the author also recognizes the lack of information on the impact caused by social programs in developing countries, and on the use of these results for decisionmaking in public policy matters (Cardozo Brum, 2006; World Bank, 2004a). Acosta, (2010) points out the divergence between the social indicators generated by Coneval, and the objectives and results obtained from social policies, and mentions that evaluation in Mexico has not yet been able to provide answers to the public and social actors in matters related to the compliance with these objectives; emphasizing that Coneval's excessive dependence on the federal government hinders the fulfillment of its primary purpose.

Another challenge of evaluations in Mexico is that they lack consistency and heterogeneity. The above can be observed in the quality of the products published by the 
agency Evalua Jalisco ${ }^{4}$, which are characterized by lacking the theoretical basis of the evaluation and which are focused on administrative and financial processes, resulting in products that do not contribute to the generation of knowledge .

In terms of social participation and accountability, Mexico is still lagging behind. In this sense, it is necessary to improve both practices in order to increase the involvement of society in the evaluation and monitoring process of social programs.

Finally, Stockmann \& Meyer, (2016) recognize that the future of the discipline of evaluation lies in professionalization of the field. That is, to formalize the discipline through educational programs taught at universities and training courses that promote academic production increase, and therefore national contribution to the literature of evaluation theory. This process implies that the evaluators must have basic training and sufficient experience to perform in the field.

\section{References}

Acosta, F. (2010) 'La evaluación de la política social en México: Avances recientes, tareas pendientes y dilemas persistentes', Papeles de Poblacion, 16(64), pp. 155-188. Cardozo Brum, M. I. (2006) Evaluacion de politicas y programas publicos: El caso de los programas de desarrollo social en México. Available at:

http://biblioteca.diputados.gob.mx/janium/bv/ce/scpd/LIX/eval_pol_prog_pub.pdf.

Cardozo Brum, M. I. (2013) 'De la evaluación a la reformulación de políticas públicas', Política y Cultura, 40(Otoño), pp. 123-149. Available at:

http://148.206.107.15/biblioteca_digital/estadistica.php?id_host=6\&tipo=ARTICULO\&id=9 312\&archivo=8-643-9312eja.pdf\&titulo=De la evaluación a la reformulación de políticas públicas.

Cohen, E. (2001) Reforma del Estado, modernización administrativa y evaluación del desempeño de la gestión. Santiago de Chile. Available at:

http://repositorio.cepal.org/handle/11362/6000.

Consejo Nacional de Evaluación de la Política de Desarrollo Social (2017) Informe de Evaluación de la Política de Desarrollo Social 2016. Ciudad de México.

DIARIO OFICIAL DE LA FEDERACIÓN (2004) 'Ley General de Desarrollo Social'. Hogan, L. R. (2007) 'The historical development of program evaluation: Exploring the past and present', Online Journal of Workforce Education and Development, II(4), pp. 110.

Madaus, G. F., Stufflebeam, D. L. and Kellaghan, T. (2000) Evaluation models:

Viewpoints on educational and human services evaluation. Second. Hingham, MA: Kluwer Academic Publishers.

Mundial, B. (no date) La pobreza en México, una evaluación de las condiciones, las

\footnotetext{
${ }^{4}$ Evalua Jalisco is an organization that belongs to the Government of the State of Jalisco and that promotes an evaluation strategy in a structured, accessible and friendly manner. Its objective is to improve the efficiency of the programs and public policies implemented by the different agencies and entities of the Executive Power, based on the generation of evidence that facilitates decision-making.
} 
tendencias y la estrategia del gobierno. México.

Pérez, D. (2007) 'Revisión y análisis del Modelo de Evaluación Orientada en los Objetivos (Ralph Tyler - 1950)', (January). Available at:

https://www.researchgate.net/publication/220025586_Revision_y_analisis_del_Modelo_d e_Evaluacion_Orientada_en_los_Objetivos_Ralph_Tyler_-_1950.

Pérez, Y. and Maldonado Trujillo, C. (eds) (2015) Panorama de los sistemas nacionales de monitoreo y evaluación en América Latina. Primera. CIDE. Available at:

http://www.libreriacide.com/?P=producto\&PRODfamily=libros\&PRODclassification=6\&PR ODproduct $=1075161 \#$. WYzpg1G25aQ.

Stockmann, R. and Meyer, W. (2016) 'The Future of Evaluation: Global Trends, New Challenges and Shared Perspectives', in Stockmann, R. and Meyer, W. (eds) The Future of Evaluation. Global Trends, New Challenges, Shared Perspectives. New York: Palgrave Macmillan, pp. 9-19. doi: 10.1057/9781137376374.

Stufflebeam, D. L. and Coryn, C. L. S. (2014) Evaluation, Theory, Models, \& Applications. Second. San Francisco: Jossey-Bass. 